\title{
MOTIVATION LEVEL AND ITS COMPARISON BETWEEN SENIOR MANAGERS AND BLUE-COLLAR WORKERS IN SMALL AND MEDIUM-SIZED TRANSPORT ENTERPRISES
}

The aim of the article is to compare the motivation level of senior managers and blue-collar workers in Slovak small and medium-sized enterprises providing transport for forestry sector with the focus on the creation of motivation programs. The analysis included 340 senior managers and 262 blue-collar workers. A total of 30 motivation factors were examined. The most important motivation factors were defined. We identified the significant differences between the needs of senior managers and blue-collar workers by using the Student two-sample t-test. Based on the results of our testing we may conclude that in the field of motivation factors in Slovakia it is not possible to establish a uniform motivation program for the analyzed groups of employees. In the future, after meeting the needs of employees, it is possible that motivation may change with the change of requirements.

Keywords: employee motivation, motivation program, job satisfaction, work position, student two - sample $t$ - test

\section{Introduction}

Due to the fact that every business is based on the work of human beings, the main objective of the human resources management is to create conditions for effective implementation of the business concept by maximizing the performance of its employees. Any company may have at its disposal a top-level technology, rich financial resources, and scarce information, but its success and competitiveness only depend on high-quality and qualified employees [1]. Whereas in 1999 the emphasis was laid upon productivity growth, the development of senior management took priority in 2004, while employee satisfaction and motivation have been the center of interest of personnel professionals since 2004 [2, 3]. Currently, human resources are strategically important for each company. If we realize that human resources are the basis of enterprise development, then human resources management is the key to business success [4]. The principal task of human resource management is to ensure positive behavior of employees. Satisfied and positively motivated employees, having their own interest in the prosperity of the company, can guarantee the success of the company the same as systematic motivation and motivational processes support effective work of employees.
In recent years, employee motivation has become a determining factor for the success of any organization. It is, therefore, necessary to actively build and declare the company's positive relation to employees and employees' relation to the company [5]. Work motivation is more complicated because people have different needs and aspirations. Therefore, they are motivated differently. Employee motivation is linked closely to the human resources as they can affect the company performance. Nedeliakova, et al. [6], Yuanhua, et al. [7] and $\mathrm{Wu}$ et al. [8] emphasize that employees are an important asset for any organization. They should be motivated relative to the changing context of the organization in which they work. Work motivation depends on the job, as well as on age, gender, education, job position and other factors which grow in importance particularly at management level. Eskildsen and Nussler [9] found out that the reason for the relatively high level of work motivation could be that highly educated employees were held to higher positions, more diverse and more demanding tasks. The differences are greater when married women and men with dependent children are compared. According to DeMartino and Barbato [10], the percentage difference between these two groups increases by every motivational incentive in their career.

\footnotetext{
* ${ }^{1}$ Rudolf Kampf, ${ }^{2}$ Silvia Lorincova, ${ }^{3}$ Larisa M. Kapustina, ${ }^{1}$ Lenka Lizbetinova

${ }^{1}$ Faculty of Technology, The Institute of Technology and Business in Ceske Budejovice, Czech Republic

${ }^{2}$ Faculty of Wood Sciences and Technology, Technical University in Zvolen, Slovakia

${ }^{3}$ Ural State University of Economics, Yekaterinburg, Russia

E-mail: kampf@mail.vstecb.cz
} 
Employee motivation and engagement has always been a major concern for research [11]. Leete [12] found that nonprofit organizations rely on internally motivated employees unduly. Based on Buelens and Van den Broeck [13], public sector employees are more often motivated intrinsically. Public sector employees are more motivated by workload, personal growth, recognition, individual decision-making, interesting work and an opportunity to learn something new [14]. Hitka and Balazova [15] assume that employees with higher education and a higher level of seniority prefer different motivation factors from employees with lower education and less seniority. Freund's research [16] is based on younger adults, particularly college students who want to acquire new knowledge and skills to enable them to get a degree and get a job. College students are motivated to succeed and seek to optimize their performance. However, it is not known if the emphasis on optimizing is also true for senior employees [17]. According to Moon [18], public sector managers have a lower level of loyalty to the organization than managers of the private sector, especially when it comes to their willingness to make a further effort. Bolfikova et al. [19] confirm that the behavior of the manager depends on the performance, and that flexible and dynamic behavior, management styles and techniques differ from organization to organization. Manager behavior depends on the decision-making process as well. It can have an impact on the motivation level of employees. Based on those arguments, it is clear that work motivation among employees varies. It is likely that adults with higher levels of education are able to work independently and to develop more. Older workers with higher education do not need to spend so much effort on their expertise to achieve the same performance as their younger co-workers with lower education. Thus, acquisition of new knowledge is easier if it is compatible with the existing framework, necessary training, and experience.

The company motivation program is a comprehensive set of measures in the field of human resources management. It is built on management activities, actively influences job performance, and creates or strengthens positive attitudes of all employees. In this respect, the goal is to reinforce the identification of the employees' interests with the interests of the company (loyalty to one's own business) and the formation of employee interest in the development of their own abilities, knowledge, and skills, actively used in the work process [20]. This is based on the assumption that the development of creative abilities of human potential and its engagement in enterprise benefits is the best guarantee for the successful fulfillment of its fundamental objectives and that it survives in the difficult conditions of the market environment. In enterprises, individual or group motivation programs are often used as part of adjustment programs to achieve the required level of employee performance. By their implementation and integration into internal corporate documents, the motivation programs are expected to change the overall approach to the role of employees in an enterprise.
Sumita [21] says that in today's competitive environment, the number of enterprises is increasing. Companies compete with one another. The interest in excellent employees is constantly growing. Therefore, it is inevitable to maintain high employee productivity through rewards. Grazulis and Baziene [22] and Kucharcikova [23] claim that the theory of human capital deals with increasing the economic value of human resources (adding value to human capital) through investment into resources, especially through education. The importance of remuneration may vary depending on the context. Employees who fulfill basic needs prefer financial reward, while others tend to seek reward and recognition in another form. To obtain benefits from the concept of remuneration, it is essential to provide processes in companies that are fair and reasonable to the market.

\section{Methodology}

The randomly addressed senior managers and bluecollar workers in Slovak small and medium-sized enterprises providing transport for forestry sector were asked to complete the questionnaires. The sampling unit consisted of 340 senior managers and 262 blue-collar workers. To obtain empirical data and to verify the established hypotheses, the questionnaire method was used as the main technique. The questionnaires were distributed via e-mail. For maximum comprehensibility, the questionnaire was created in the uniform format for all categories of employees. The respondents were informed about anonymity in advance. The questionnaire consisted of two parts. The first part focused on obtaining a clearer idea of the personality through gender, work position, age, level of education and seniority in the enterprise. The second part consisted of 30 motivation factors. To avoid influencing the respondents, the motivation factors were arranged in alphabetical order. The respondents defined how important the motivation factors were for them, as well as which of these factors more or less affect their job performance. The respondents were using a five-point rating scale of the significance of each motivation factor (5-very important, 4-important, 3medium important, 2-less important, 1-unimportant).

The findings were used to process an analysis of employee motivation. Data acquisition covered the period from November 2015 to March 2016. The method of comparative analysis was used to process the experimental results. The data were processed by Statistics 10.0 software [24]. We assumed that there exist significant differences in motivation level between senior managers and blue-collar workers. Based on inductive statistics, we used Student two-sample t-test to determine the statistical significance of differences in average levels of motivation of senior managers) and blue-collar workers ${ }_{\text {всW }}$ ) at the selected level of significance $\alpha=0.05$ [25]. The null hypothesis was tested versus the alternative (Equation 1):

$H_{0}: \mu_{S M}=\mu_{B C W}$ vs. $H_{1}: \mu_{S M}=\mu_{B C W}$ 
Table 1 The structure of sampling unit

\begin{tabular}{|c|c|c|c|c|c|c|c|}
\hline \multicolumn{2}{|c|}{ Work position } & \multicolumn{2}{|l|}{ Age } & \multicolumn{2}{|c|}{ Completed education } & \multicolumn{2}{|l|}{ Seniority } \\
\hline Senior managers & 340 & Under 30 years & 95 & Primary & 40 & Less than 1 year & 30 \\
\hline \multirow[t]{4}{*}{ Blue - collar workers } & 262 & From 31 to 40 years & 182 & Lower secondary & 122 & $1-3$ years & 62 \\
\hline & & From 41 to 50 years & 210 & Upper secondary & 230 & $4-6$ years & 115 \\
\hline & & 50 years and more & 115 & Higher & 210 & $7-9$ years & 140 \\
\hline & & & & & & 10 years or more & 255 \\
\hline
\end{tabular}

Table 2 Top motivation factors ordered according to the level of importance

\begin{tabular}{|c|c|c|c|c|c|}
\hline S.N. & Top motivation factor rated by senior managers & Average & S.N. & Top motivation factor rated by blue - collar workers & Average \\
\hline 1. & Job security & 4.62 & 1. & Atmosphere in the workplace & 4.69 \\
\hline 2. & Fair appraisal system & 4.57 & 2. & Good work team & 4.65 \\
\hline 3. & Base salary & 4.54 & 3. & Work environment & 4.48 \\
\hline 4. & Fringe benefits & 4.43 & 4. & Fringe benefits & 4.42 \\
\hline 5. & Supervisor's approach & 4.40 & 5. & Working hours & 4.37 \\
\hline 6. & Atmosphere in the workplace & 4.34 & 6. & Relation to the environment & 4.37 \\
\hline 7. & Good work team & 4.28 & 7. & Fair appraisal system & 4.33 \\
\hline 8. & Name of the company & 4.25 & 8. & Job performance & 4.29 \\
\hline 9. & Working hours & 4.25 & 9. & Mental effort & 4.29 \\
\hline 10. & Communication in the workplace & 4.24 & 10. & Mission of the company & 4.29 \\
\hline
\end{tabular}

$\mathbf{H}_{0}$ : we suppose that the importance level of the selected motivation factors of senior managers is equal to the importance level of the selected motivation factors of blue-collar workers.

$\mathbf{H}_{\mathbf{1}}$ : we suppose that the importance level of the selected motivation factors of senior managers is not equal to the importance level of the selected motivation factors of blue-collar workers.

\section{Results and discussion}

In the research, 1.800 questionnaires were distributed. The questionnaire response rate was $33.44 \%$ (602 correctly completed questionnaires). The sampling unit consisted of employees working in small and medium-sized enterprises providing transport for forestry sector operating all over the Slovak Republic. Table 1 shows the sociological overview of 602 respondents ( 512 men and 90 female) in terms of work position, age, completed education and seniority.

The aim of the research was to compare the motivation level of senior managers and blue-collar workers in Slovak small and medium-sized enterprises providing transport for the forestry sector. Based on the results, we could define the hierarchy of motivation factors for the group of senior managers and the group of blue-collar workers. Table 2 presents 10 motivation factors that acquired the highest values of the selected averages.
Based on the collected data, senior managers considered job security the most important motivation factor. Subsequently, there were motivation factors related to financing (fair appraisal system, base salary, fringe benefits). The motivation of senior managers was affected by supervisor's approach, the atmosphere in the workplace and good work team. Blue-collar workers considered atmosphere in the workplace the most important motivation factor followed by good work team and work environment. Hypothesis testing was evaluated due to the significance of differences of averages according to the importance of individual motivation factors (Table 3). Within the hypothesis, we assumed that there exist differences in the motivation level of senior managers and blue-collar workers.

Table 3 shows the motivation factors with differences considered statistically significant. The significant differences of arithmetic averages of motivation factors at the $5 \%$ significance level are highlighted in bold. Significant differences between senior managers and blue-collar workers were observed when analyzing the atmosphere in the workplace, good work team, job security, mental effort, mission of the company, physical effort at work, stress, supervisor's approach and work environment.

In the following step, a total of 30 motivation factors were subject to a more detailed analysis. Using statistical methods, it was verified that the work position influences the importance of motivation factors $(\mathrm{p}=0.000)$. The $p$-levels are highlighted in bold in Table 4. 


\begin{tabular}{|c|c|c|c|c|c|c|c|c|}
\hline \multicolumn{9}{|c|}{ Average } \\
\hline Motivation factor & 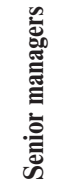 &  & 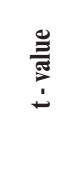 & $\frac{\bar{d}}{2}$ & 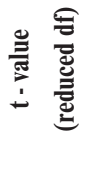 & $\frac{\bar{d}}{\dot{e}}$ & 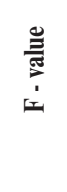 & $\frac{\bar{d}}{\dot{d}}$ \\
\hline Atmosphere in the workplace & 4.34 & 4.69 & -2.60 & 0.010 & -2.71 & 0.008 & 1.80 & 0.029 \\
\hline Base salary & 4.54 & 4.25 & 1.68 & 0.096 & 1.64 & 0.104 & 1.44 & 0.161 \\
\hline Career advancement & 4.07 & 4.21 & -0.82 & 0.411 & -0.80 & 0.425 & 1.55 & 0.092 \\
\hline Communication in the workplace & 4.24 & 4.23 & 0.03 & 0.978 & 0.03 & 0.978 & 1.04 & 0.897 \\
\hline Competences & 3.87 & 4.02 & -0.81 & 0.418 & -0.79 & 0.431 & 1.53 & 0.103 \\
\hline Fair appraisal system & 4.57 & 4.33 & 1.52 & 0.132 & 1.47 & 0.146 & 1.66 & 0.051 \\
\hline Free time & 4.13 & 4.21 & -0.51 & 0.608 & -0.50 & 0.616 & 1.41 & 0.188 \\
\hline Fringe benefits & 4.43 & 4.42 & 0.02 & 0.981 & 0.02 & 0.981 & 1.02 & 0.935 \\
\hline Good work team & 4.28 & 4.65 & -2.51 & 0.013 & -2.56 & 0.012 & 1.36 & 0.251 \\
\hline Individual decision-making & 4.09 & 4.02 & 0.41 & 0.685 & 0.39 & 0.696 & 1.72 & 0.037 \\
\hline Information about performance result & 4.06 & 4.15 & -0.59 & 0.557 & -0.58 & 0.564 & 1.29 & 0.334 \\
\hline Job performance & 4.13 & 4.29 & -1.01 & 0.313 & -0.98 & 0.327 & 1.55 & 0.091 \\
\hline Job security & 4.62 & 4.13 & 3.00 & 0.003 & 2.82 & 0.006 & 2.62 & 0.000 \\
\hline Mental effort & 3.90 & 4.29 & -2.30 & 0.023 & -2.30 & 0.023 & 1.04 & 0.893 \\
\hline Mission of the company & 3.91 & 4.29 & -2.31 & 0.022 & -2.35 & 0.022 & 1.26 & 0.388 \\
\hline Name of the company & 4.25 & 4.06 & 1.01 & 0.314 & 1.00 & 0.321 & 1.23 & 0.417 \\
\hline Opportunity to apply one's own ability & 4.13 & 3.90 & 1.35 & 0.181 & 1.31 & 0.195 & 1.56 & 0.086 \\
\hline Personal growth & 4.13 & 4.02 & 0.64 & 0.524 & 0.62 & 0.534 & 1.44 & 0.157 \\
\hline Physical effort at work & 3.50 & 4.21 & -3.63 & 0.000 & -3.80 & 0.000 & 2.01 & 0.010 \\
\hline Prestige & 3.78 & 4.00 & -1.19 & 0.237 & -1.20 & 0.233 & 1.14 & 0.636 \\
\hline Recognition & 4.18 & 4.08 & 0.68 & 0.501 & 0.66 & 0.512 & 1.45 & 0.151 \\
\hline Region's development & 3.69 & 3.96 & -1.42 & 0.159 & -1.40 & 0.164 & 1.18 & 0.514 \\
\hline Relation to the environment & 4.24 & 4.37 & -0.87 & 0.388 & -0.88 & 0.381 & 1.22 & 0.458 \\
\hline Self - fulfillment & 4.04 & 4.19 & -0.90 & 0.372 & -0.88 & 0.379 & 1.24 & 0.409 \\
\hline Social benefits & 4.16 & 4.17 & -0.07 & 0.942 & -0.07 & 0.944 & 1.52 & 0.107 \\
\hline Stress & 3.78 & 4.15 & -2.16 & 0.033 & -2.16 & 0.033 & 1.01 & 0.965 \\
\hline Supervisor's approach & 4.40 & 3.96 & 2.30 & 0.023 & 2.18 & 0.032 & 2.37 & 0.001 \\
\hline Work environment & 4.10 & 4.48 & -2.57 & 0.011 & -2.58 & 0.011 & 1.09 & 0.759 \\
\hline Working hours & 4.25 & 4.37 & -0.76 & 0.451 & -0.73 & 0.464 & 1.57 & 0.081 \\
\hline Workload and type of work & 4.18 & 4.21 & -0.23 & 0.818 & -0.23 & 0.821 & 1.21 & 0.455 \\
\hline
\end{tabular}

Based on the analysis (Table 4), there is a significant dependence between work position and motivation factors listed in Table 4 (competences, information about performance result, job security, physical effort at work, supervisor's approach). Due to the independence of the sampling unit, Student two-sample t-test was used to consider the significant differences between the needs of senior managers and blue-collar workers. The null hypothesis vs. the alternative hypothesis was tested at the selected level of significance $\alpha=0.05$. A total of 602 employees working in Slovak small and medium-sized enterprises providing transport for forestry sector were asked to identify the importance of factors that affect motivation. Senior managers considered job security the most important motivation factor. This factor is motivating in most occupations in Slovakia as researched in Hitka and Stipalova [26] and Zavadsky, et al. [27]. 
Table 4 The analysis of significant dependence between work position and motivation factors

\begin{tabular}{|c|c|c|c|c|}
\hline Motivation factor & Statistical methods & Chi - square test & Degree of freedom & p - level \\
\hline \multirow{4}{*}{ Competences } & Pearson's chi - square test & 9.458580 & $\mathrm{df}=4$ & $\mathrm{p}=.051$ \\
\hline & Maximum likelihood chi - square test & 9.523136 & $\mathrm{df}=4$ & $\mathrm{p}=.049$ \\
\hline & Pearson's contingency coefficient & .1669243 & & \\
\hline & Cramér's V. & .1692996 & & \\
\hline \multirow{4}{*}{ Information about performance result } & Pearson's chi - square test & 13.62886 & $\mathrm{df}=4$ & $p=.009$ \\
\hline & Maximum likelihood chi - square test & 14.80124 & $\mathrm{df}=4$ & $\mathrm{p}=.005$ \\
\hline & Pearson's contingency coefficient & .1991521 & & \\
\hline & Cramér's V. & .2032230 & & \\
\hline \multirow{4}{*}{ Job security } & Pearson's chi - square test & 9.456244 & $\mathrm{df}=4$ & $\mathrm{p}=.051$ \\
\hline & Maximum likelihood chi - square test & 11.09171 & $\mathrm{df}=4$ & $\mathrm{p}=.026$ \\
\hline & Pearson's contingency coefficient & .1669043 & & \\
\hline & Cramér's V. & .1692787 & & \\
\hline \multirow{4}{*}{ Physical effort at work } & Pearson's chi - square test & 17.84001 & $\mathrm{df}=4$ & $\mathrm{p}=.001$ \\
\hline & Maximum likelihood chi - square test & 18.19052 & $\mathrm{df}=4$ & $\mathrm{p}=.001$ \\
\hline & Pearson's contingency coefficient & 0.2264685 & & \\
\hline & Cramér's V. & 0.2325094 & & \\
\hline \multirow{4}{*}{ Supervisor's approach } & Pearson's chi - square test & 10.72958 & $\mathrm{df}=4$ & $\mathrm{p}=.030$ \\
\hline & Maximum likelihood chi - square test & 11.04578 & $\mathrm{df}=4$ & $\mathrm{p}=.026$ \\
\hline & Pearson's contingency coefficient & .1774542 & & \\
\hline & Cramér's V. & .1803160 & & \\
\hline
\end{tabular}

Blue-collar workers considered the atmosphere in the workplace the most important motivation factor followed by good work team and work environment. Among senior managers, surprisingly, the name of the company was rated in top 10 most important motivation factors. It represents a high level of loyalty status. But, based on the research of Hitka and Balazova [15] and Hitka, et al. [28], this factor was the least preferred in many other areas of the economy of Slovakia. Similar research performed in 2009-2011 pointed out that base salary, job security, fringe benefits, the atmosphere in the workplace and good work team were preferred motivation factors in the Slovak wood industry. The atmosphere in the workplace, good work team, supervisor's approach, job security and base salary were preferred motivation factors by senior managers [27].

Based on the collected data, it can be concluded that significant differences were identified in 9 motivation factors (atmosphere in the workplace, good work team, job security, mental effort, mission of the company, physical effort at work, stress, supervisor's approach, work environment). In addition, there exists a significant dependence between work position and competences, information about performance result, job security, physical effort at work, supervisor's approach. Differences of senior managers and blue-collar workers can be caused by the workload and type of work. Senior managers work mostly indoors, while blue-collar workers mostly work physically outdoors. Mental effort and mission of the company influenced senior managers in Slovak small and medium-sized enterprises providing transport for the forestry sector. Blue-collar workers were influenced by the physical effort at work and the supervisor's approach. Therefore, in the creation of a motivation program focused on each group analyzed, it is necessary to differentiate specific requirements of both groups as well as respect the needs arising at work. The investments in the creation of the motivation program are longterm investments. In terms of time, the motivation level does not change radically. Individualization of the motivation program using motivation factors related to self-fulfillment and personal ambitions of individual employees is another option. However, this method increases costs greatly.

\section{Conclusions}

Currently, many enterprises do not consider motivation, development, and education of employees important. It is often a question of finance, or employees are not interested in this area. Based on the analysis, a conclusion can be provided. Due to the diversity of work environment in Slovak small and mediumsized enterprises providing transport for the forestry sector, it is not possible to establish a uniform motivation program for the analyzed groups of employees. The motivation program specific 




for senior managers should be related to finance as well as to the atmosphere in the workplace, good work team, communication in the workplace and supervisor's approach. Similarly, the motivation program specific for blue-collar workers should be focused on the atmosphere in the workplace, good work team, communication in the workplace, supervisor's approach, as well as on the physical effort at work, occupational safety, job security, workload and type of work, information about performance result, working hours, work environment, job performance, mental effort and stress. It is difficult to define an effective motivation program. Since the motivation of employees may change over time, the company should deal with motivation continually. The motivation program should be continually updated after fulfilling motivation needs. However, costs may be increased by these changes. The motivation program can be concentrated on process management as well as on recognition and communication in the workplace [28].

\section{Acknowledgements}

This research was supported by VEGA 1/0024/17 and APVV16-0297.

\section{References}

[1] HITKA, M., SIROTIAKOVA, M.: The Impact of Economic Crisis on the Change in Motivation of Furniture Company Employees. Drewno, 54(185), 119-126, 2011.

[2] OLSOVSKA, A., MURA, L., SVEC, M.: Personnel Management in Slovakia: An Explanation of the Latent Issues. Polish Journal of Management Studies, 13(2), 110-120, 2016.

[3] ZAMECNIK, R.: Personnel Controlling as a Part of the Management Controlling System in an Enterprise. E a M: Ekonomie a Management, 10(2), 29-36, 2007.

[4] BAGSHAWE, A.: How to Improve Motivation. Antony Bagshawe \& Ventus Publishing ApS, 2011.

[5] STACHOVA, K., STACHO, Z., BARTAKOVA, G. P.: Influencing Organizational Culture by Means of Employee Remuneration. Business: Theory and Practice, 16(3), 264-270, 2015.

[6] NEDELIAKOVA, E., MASEK, J., SEKULOVA, J.: Innovative Approach in System of Teaching Management in Field of Railway Transport. Turkish Online Journal of Educational Technology, 306-311, 2015 (view additional authors).

[7] YUANHUA, H., SHENHUA, Z., JIANHUA, J.: The Study on the Motivation Mode of Knowledge Transfer from Employee to Organization. International Conference on Management Innovation, 1(2), 229-237, 2007.

[8] WU, H., L., SU, W., CH., LEE, CH., Y.: Employee Ownership Motivation and Individual Risk-Taking Behavior: A Cross-Level Analysis of Taiwan's Privatized Enterprises. International Journal of Human Resource Management, 19, 2311-2331, 2008.

[9] ESKILDSEN, J., K., NUSSLER, M., L.: The Managerial Drivers of Employee Satisfaction and Loyalty. Total Quality Management, 11(4-6), 581-588, 2003

[10] DEMARTINO, R., BARBATO, R.: Differences between Women and Men MBA Entrepreneurs: Exploring Family Flexibility and Wealth Creation as Career Motivators. Journal of Business Venturing, 18(6), 815-832, 2003.

[11] SANYAL, M., K., BISWAS, S., B.: Employee Motivation from Performance Appraisal Implications: Test of a Theory in the Software Industry in West Bengal (India). Procedia Economics and Finance, 11, 182-196, 2014.

[12] LEETE, L.: Wage Equity and Employee Motivation in Nonprofit and For - Profit Organizations. Journal of Economic Behavior \& Organization, 43(4), 423-446, 2000.

[13] BUELENS, M., VAN DEN BROECK, H.: An Analysis of Differences in Work Motivation between Public and Private Sector Organizations. Public Administration Review, 67(1), 65-74, 2007.

[14] URBANCOVA, H., HUDAKOVA, M.: Employee Development in Small and Medium Enterprises in the Light of Demographic Evolution. Acta Universitatis Agriculturae et Silviculturae Mendelianae Brunensis, 63, 1043-1050, 2015.

[15] HITKA, M., BALAZOVA, Z.: The Impact of Age, Education and Seniority on Motivation of Employees. Business: Theory and Practice, 16(1), 113-120, 2015.

[16] FREUND, A., M.: Age - Differential Motivational Consequences of Optimization versus Compensation Focus in Younger and Older Adults. Psychology and Aging, 21(2), 240-252, 2006.

[17] KUCHARCIKOVA, A., KONUSIKOVA, L., TOKARCIKOVA, E.: Approaches to the Quantification of the Human Capital Efficiency in Enterprises. Communications-Scientific Letters of the University of Zilina, 18(1A), 49-54, 2016.

[18] MOON, M., J.: Organizational Commitment Revisited in New Public Management: Motivation, Organizational Culture, and Managerial Level. Public Performance and Management Review, 24(2), 177-194, 2000. 
[19] BOLFIKOVA, E., HREHOVA, D., FRENOVA, J.: Manager's Decision-Making in Organizations-Empirical Analysis of Bureaucratic vs. Learning Approach. Radova Ekonomskog Fakultet au Rijeci, 28(1), 135-163, 2010.

[20] HEWITT, A., LARSON, S.: The Direct Support Workforce in Community Supports to Individuals with Developmental Disabilities: Issues, Implications and Promising Practices. Mental Retardation and Developmental Disabilities Research Reviews, 13(2), 178-187, 2007.

[21] SUMITA, R.: Motivational Theories and Incentives Approaches. Indian Institute of Management Bangalore Management Review, 16(4), 43-50, 2014.

[22] GRAZULIS, V., BAZIENE, B.: Employees' Socialization in Lithuanian Preschools-Myth or Reality (Situational Analysis). Filosofija, Sociologija, 20(4), 345-355, 2009.

[23] KUCHARCIKOVA, A.: The Importance of Identification and Analysis of Educational Needs for Investment in Human Capital. Communications - Scientific Letters of the University of Zilina, 16(3), 86-92, 2014.

[24] MASON, R., D., LIND, D., A.: Statistical Techniques in Business and Economics. Irwin, New York, 1990.

[25] SCHMIDTOVA, J., VACEK, V.: Applied Statistics. Technical University in Zvolen, 2013.

[26] HITKA, M., STIPALOVA, L.: Comparing Level of Employee's Motivation in Wood Processing Businesses with Manufacturing Companies in Slovak Republic. Drvna industria, 62(3), 185-192, 2011.

[27] ZAVADSKY, J., HITKA, M., POTKANY, M.: Changes of Employee Motivation of Slovak Enterprises Due to Global Economic Crisis. E a M: Ekonomie a Management, 18(1), 57-66, 2015.

[28] HITKA, M., STACHOVA, K., BALAZOVA, Z., STACHO, Z.: Differences in Employee Motivation at Slovak Primary Schools in Rural and Urban Areas. International education studies, 8(5), 33-42, 2015. 